\title{
Assessing the impact of screening, brief intervention, and referral to treatment implementation on attitudes toward and moralization about alcohol, tobacco, and other drug use
}

\author{
Telmo Ronzani ${ }^{1 *}$, Marina Oliveira ${ }^{1}$, Daniela Mota ${ }^{1}$, Erica Cruvinel${ }^{2}$, Tamires Laport ${ }^{1}$, Leonardo Martins ${ }^{2}$ \\ From International Network on Brief Interventions for Alcohol Problems (INEBRIA) Meeting 2011 \\ Boston, MA, USA. 21-23 September 2011
}

Screening, brief intervention, and referral to treatment (SBIRT) dissemination has been presented as a way to change medical professionals' attitudes toward adopting prevention practices for alcohol and other drug use. We evaluated the impact of SBIRT dissemination on attitudes related to preventive practices for alcohol consumption and on the moralization of alcohol and other drug use by primary care professionals $(\mathrm{N}=123)$ in two Brazilian cities. Eighty-two participants received SBIRT training (intervention group), while 41 received no SBIRT training (control group). At baseline and three-month follow-up, both groups completed scales of beliefs and attitudes regarding SBIRT implementation and another scale about the moralization of tobacco, alcohol, marijuana, cocaine, and crack use. The intervention group showed an increase in the perception of obstacles to screening implementation at follow-up assessment $(\mathrm{p}<0.05)$. Regarding moralization, the intervention group had lower moralization for crack consumption than controls at follow-up $(\mathrm{p}<0.05)$. The other measures showed no significant differences. According to these results, SBIRT training and three months of practice supervision were not sufficient to promote changes in primary care professionals' attitudes toward drug and alcohol screening or to reduce substance use moralization. These findings are relevant to research related to SBIRT dissemination, since merely learning SBIRT techniques without attitudinal changes and

'Department of Psychology, Federal University of Juiz de Fora, Juiz de Fora, Brazil

Full list of author information is available at the end of the article moralization reduction compromises the quality and effectiveness of those practices with regard to alcohol and other drug use.

\section{Author details}

'Department of Psychology, Federal University of Juiz de Fora, Juiz de Fora, Brazil. ${ }^{2}$ Department of Social Psychology and Public Health, Federal University of Juiz de Fora, Juiz de Fora, Brazil.

Published: 9 October 2012

doi:10.1186/1940-0640-7-S1-A69

Cite this article as: Ronzani et al: Assessing the impact of screening, brief intervention, and referral to treatment implementation on attitudes toward and moralization about alcohol, tobacco, and other drug use. Addiction Science \& Clinical Practice 2012 7(Suppl 1):A69.

Submit your next manuscript to BioMed Central and take full advantage of:

- Convenient online submission

- Thorough peer review

- No space constraints or color figure charges

- Immediate publication on acceptance

- Inclusion in PubMed, CAS, Scopus and Google Scholar

- Research which is freely available for redistribution
C Biomed Central

( 2012 Ronzani et al; licensee BioMed Central Ltd. This is an Open Access article distributed under the terms of the Creative Commons Attribution License (http://creativecommons.org/licenses/by/2.0), which permits unrestricted use, distribution, and reproduction in any medium, provided the original work is properly cited. 